\title{
High Stability and Long Cycle Life of Rechargeable Sodium-lon Battery Using Manganese Oxide Cathode: A Combined Density Functional Theory (DFT) and Experimental Study
}

Bidhan Pandit,* Sachin R. Rondiya, Nelson Y. Dzade, Shoyebmohamad F. Shaikh, Nitish Kumar, Emad S. Goda, Abdullah A. Al-Kahtani, Rajaram S. Mane, Sanjay Mathur, and Rahul R. Salunkhe*

Gite This: ACS Appl. Mater. Interfaces 2021, 13, 11433-11441

Read Online

ACCESS | Lill Metrics \& More | 国 Article Recommendations | * Supporting Information

ABSTRACT: Sodium-ion batteries (SIBs) can develop costeffective and safe energy storage technology for substantial energy storage demands. In this work, we have developed manganese oxide $\left(\alpha-\mathrm{MnO}_{2}\right)$ nanorods for SIB applications. The crystal structure, which is crucial for high-performance energy storage, is examined systematically for the metal oxide cathode. The intercalation of sodium into the $\alpha-\mathrm{MnO}_{2}$ matrix was studied using the theoretical density functional theory (DFT) studies. The DFT studies predict $\mathrm{Na}$ ions' facile diffusion kinetics through the $\mathrm{MnO}_{2}$ lattice with an attractively low diffusion barrier $(0.21 \mathrm{eV})$. When employed as a cathode material for SIBs, $\mathrm{MnO}_{2}$ showed a

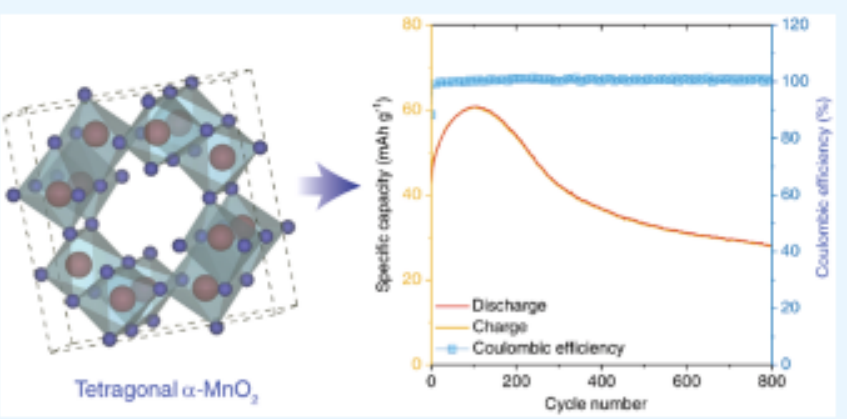
moderate capacity (109 $\mathrm{mAh} \cdot \mathrm{g}^{-1}$ at $\mathrm{C} / 20$ current rate) and superior life cyclability ( $58.6 \%$ after 800 cydes) in $\mathrm{NaPF}_{6} / \mathrm{EC}+\mathrm{DMC}$ ( $5 \% \mathrm{FEC}$ ) electrolyte. It shows a much higher capacity of 181 $\mathrm{mAh} \cdot \mathrm{g}^{-1}$ (C/20 current rate) in $\mathrm{NaClO}_{4} / \mathrm{PC}$ ( $\left.5 \% \mathrm{FEC}\right)$ electrolyte, though it suffers fast capacity fading ( $11.5 \%$ after $\left.800 \mathrm{cycles}\right)$. Our findings show that high crystallinity and hierarchical nanorod morphology of the $\mathrm{MnO}_{2}$ are responsible for better cycling performance in conjunction with fast and sustained charge-discharge behaviors.

KEYWORDS: $\mathrm{MnO}_{2}$, Rietvdd refinement, DFT analysis, sodium-ion battery, life-cycle performance

\section{INTRODUCTION}

The ever-increasing need for clean energy is driving the demand for large-scale energy storage devices made of earthabundant, cost-effective, and environmentally benign materials. The lithium-ion battery (LB) is the most perfected technology and a feasible option for short-to-medium scale energy solutions among existing battery technologies. ${ }^{1-5}$ It is useful in terms of high theoretical capacity $\left(3860 \mathrm{mAh} \cdot \mathrm{g}^{-1}\right),{ }^{6}$ cycle stability ( 30000 charge-discharge cycles), ${ }^{7}$ and excellent rate capability. ${ }^{8}$ However, concems about LIB safety, lifetime, and high cost limit its large-scale deployment. ${ }^{9}$ Although recycling of LIBs provides an attractive solution to reuse lithium, it is not a feasible solution considering the massive requirements for electric vehicles (EVs) and many other electric appliances. ${ }^{10}$ Thus, altemative battery technologies beyond LIBs is necessary to meet the goal of energy storage.

Sodium-ion batteries (SIBs) have emrged as promising alternatives for LIBs because sodium is widely available and exhibits similar properties as lithium. ${ }^{11}$ However, the larger ion size of sodium $(\mathrm{Na}, 1.02 \AA \text { compared to } \mathrm{Li}, 0.76 \AA)^{12}$ and its higher ionization potential limit sodium for insertion into crystalline materials and energy density. Very recent investigations demonstrated that open structures could generally better accommodate the more abundant $\mathrm{Na}^{+}$ion in terms of phase stability. ${ }^{13,14}$ However, suitable electrode material for SIBs remains elusive. For further advancement in $\mathrm{Na}$ intercalation compounds, the development of novel materials by cost-effective and green synthesis routes is a practical solution. It is essential to mention that $\mathrm{Na}$ ions cannot easily intercalate into the graphite nanoarchitecture (while shown for other carbon nanostructures). ${ }^{15}$ This calls for developing new positive electrode (cathode) materials that largely determine the capacity, power density, and cyclability. An extensive search for new and advanced cathode materials has led to different crystalline materials and chemical compositions.

Among various transition metal oxides, manganese oxide has attracted significant attention because of the diversity of chemical compositions and structures existing in the $\mathrm{Mn}: \mathrm{O}$ phase diagram. Also, the variable oxidation states of manganese

Received: November 26, 2020

Accepted: February 4, 2021

Published: February 25, 2021

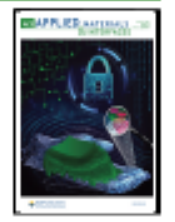



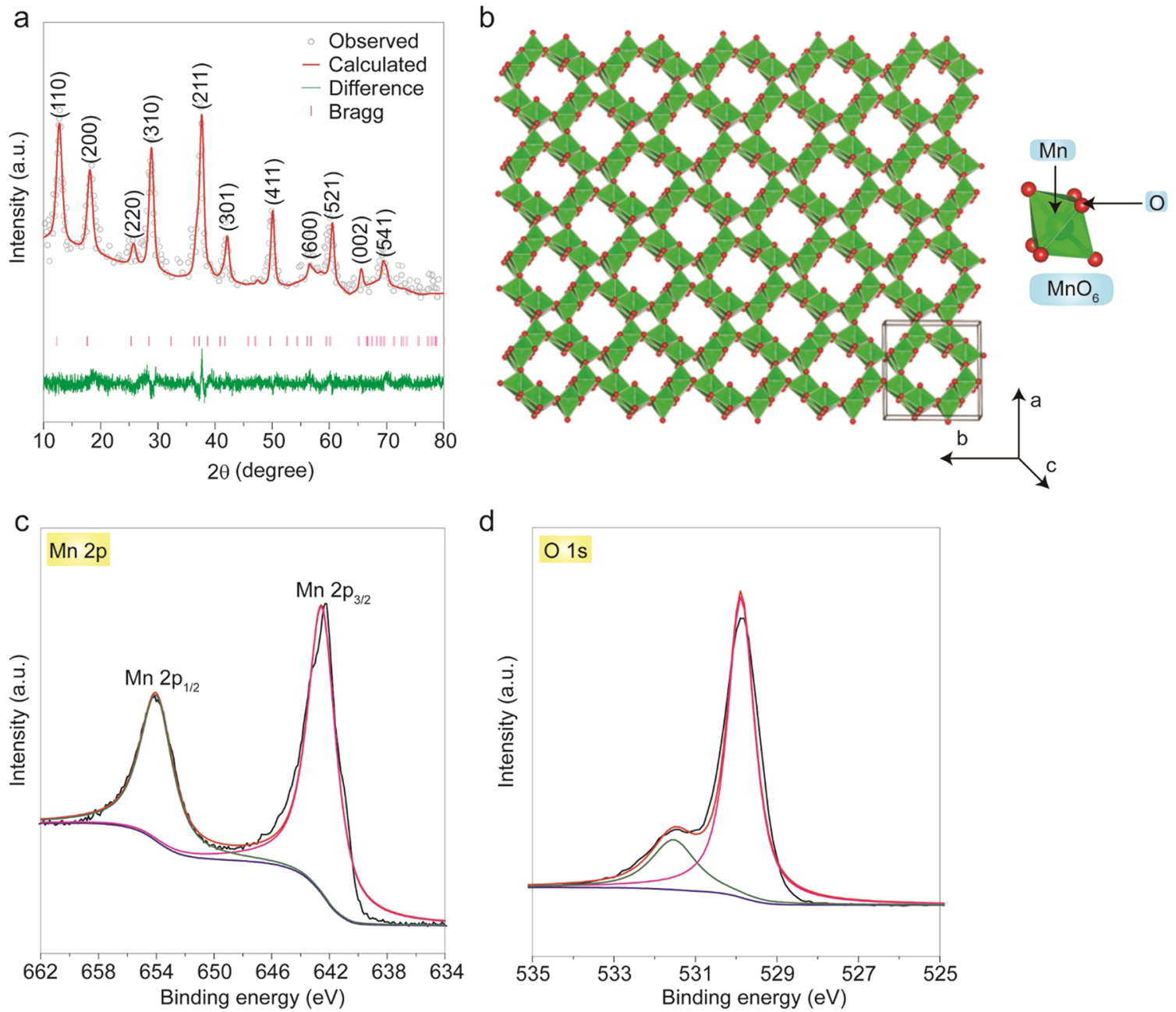

Figure 1. Structural analysis of $\mathrm{MnO}_{2}$ nanorods. (a) Rietveld refinement showing data points (light gray circles), calculated profile (red line), Bragg peak positions (pink vertical lines), and difference profile (green line), as indicated. Refined parameters are $a=b=9.815 \AA, c=2.847 \AA$, and $\alpha=\beta$ $=\gamma=90^{\circ}$ with a unit cell volume of $274.264 \AA^{3}$. (b) Crystal structure showing the species galleries for $\mathrm{Na}^{+}$intercalation between $\mathrm{MnO}_{2}$ layers. A dark green color indicates the $\mathrm{MnO}_{2}$ layers. Small red spheres represent the oxygen atoms, and the $\mathrm{Mn}$ atoms in $\mathrm{MnO}_{6}$ polyhedra are depicted in green color. (c) $\mathrm{Mn} 2 \mathrm{p}$ and (d) O 1 s XPS spectra of $\mathrm{MnO}_{2}$ sample.

can generate more than one electron in redox reactions. The other promising electrode properties include elemental abundance, low cost, easily tuned electrochemical properties, and low toxicity. ${ }^{16}$ Manganese oxides $\left(\mathrm{MnO}_{2}\right)$ have large-sized channels that could facilitate $\mathrm{Na}$ ion intercalation. ${ }^{17}$ Other studies for $\mathrm{MnO}_{2}$ showed a capacity of $\sim 130 \mathrm{mAh} \cdot \mathrm{g}^{-1}$ along with stable cycling performance. ${ }^{18-20}$ For instance, the first cycle capacity of $150 \mathrm{mAh} \cdot \mathrm{g}^{-1}$ was reported for layered P2$\mathrm{Na}_{0.6} \mathrm{MnO}_{2}{ }^{21}$ Another study showed a reversible size of 156 $\mathrm{mAh} \cdot \mathrm{g}^{-1}$ with high Coulombic efficiency for $\mathrm{Na}_{2 / 3} \mathrm{Fe}_{1 / 2}$ $\mathrm{Mn}_{1 / 2} \mathrm{O}_{2} @$ graphene composites via a filtration process; ${ }^{22}$ however, these materials showed more than $50 \%$ capacity loss after only a few tens of cycles. In this context, manganese dioxide with different polymorphs and large open channels can accommodate guest cations. ${ }^{23} \mathrm{Up}$ to now, the literature reports suggested that $\mathrm{MnO}_{2}$ could be a potential candidate for Na-ion batteries; however, cycling stability is a persisting issue for all of them.

Moreover, suitable electrolytes exhibiting good ionic conductivity, a sizable potential window, no reactivity toward the cell components, low toxicity, and a large thermal stability window are prerequisites for new cathode materials. ${ }^{24,25}$ These features depend on the solvent(s), nature of salt, and their additives. As for other technologies, SIB electrolytes require solvents with a wide range of liquid temperature, the high value of dielectric constant $\left(\varepsilon_{r}\right)$, low desolvation energy, low viscosity, chemical stability against electrode material, wide electrochemical window, and the ability to build a stable and suitable solid electrolyte interface (SEI). ${ }^{26}$ Cyclic and linear carbonates, mostly propylene carbonate (PC), ethylene carbonate (EC), and dimethyl carbonate (DMC), have been proposed as solvents for electrolytes. ${ }^{27,28}$ By comparison with lithium counterparts, $\mathrm{NaClO}_{4}$ and $\mathrm{NaPF}_{6}$ and more complex sodium salts were employed for this study. It is possible to avoid solvent molecules' co-insertion by the stable surface film. ${ }^{29}$ As SEI film is useful to prevent co-insertion, its stability is critical for the cycle life of the material. ${ }^{30}$ Furthermore, to reduce the capacity loss and improve the cycle life, changing the surface composition by adding some film-forming additives is required. They are chosen specifically to create an SEI on the negative electrode, which passivates it and allows capacity retention upon cycling. For instance, Fluoro Ethylene Carbonate (FEC) has been a popular and most advantageous additive in SIBs as it could improve the efficiency and stability of half-cells. $^{31,32}$ However, it introduces cell polarization. ${ }^{27,33}$ It is reported as a beneficial additive because of the formation of 
a more stable SEI film. ${ }^{34}$ Thus, additives play a vital role in improving SEI film stability. ${ }^{35}$

In the present study, the influence of anions on the performance of SIBs by comparing $\mathrm{Na}$ salts containing different counterions such as hexafluorophosphate $\left(\mathrm{PF}_{6}^{-}\right)$ and perchlorate $\left(\mathrm{ClO}_{4}^{-}\right)$is studied. These two $\mathrm{Na}$ salts are common salts having the advantage of the differences in anion size $\left(\mathrm{PF}_{6}{ }^{-}=0.51 \mathrm{~nm}, \mathrm{ClO}_{4}^{-}=0.49 \mathrm{~nm}\right)$, comparatively stable anion structures, and ionic conductivities. First, the influence of electrolytes was carefully studied using a half-cell configuration (vs Na metal). Further, to evaluate the individual contributions of electrolytes to the individual electrodes, a comparative survey of electrolytes prepared using solvent (PC) and a solvent mixture (EC:DMC) combined with different $\mathrm{Na}$ salts, $\mathrm{NaClO}_{4}$, and $\mathrm{NaPF}_{6}$ was carried out. The electrolyte mainly controls the transport properties and adsorption behavior on the electrode surface. Thus, our results demonstrate that the electrolytes play a significant role in achieving high energy density along with good cycle life.

\section{RESULTS AND DISCUSSION}

Crystal Structure and Morphology Analysis. The Raman spectrum (Figure S1) of the sample was measured in the frequency range of $100-1100 \mathrm{~cm}^{-1}$. The spectrum of $\alpha$ $\mathrm{MnO}_{2}$ exhibited three prominent bands at 179,583 , and 641 $\mathrm{cm}^{-1}$. The $\mathrm{Mn}-\mathrm{O}$ symmetric stretching vibrations of the $\left[\mathrm{MnO}_{6}\right]$ octahedron leads to a peak around $641 \mathrm{~cm}^{-1}$. The peak $583 \mathrm{~cm}^{-1}$ is due to $\mathrm{Mn}-\mathrm{O}$ stretching vibrations. ${ }^{36}$ The peak at $179 \mathrm{~cm}^{-1}$ is ascribed to external vibration of the $\left[\mathrm{MnO}_{6}\right]$ octahedral. ${ }^{37}$ Figure 1a shows the XRD patterns of the $\mathrm{MnO}_{2}$ nanorods with diffraction peaks at $12.90^{\circ}, 18.21^{\circ}$, $25.76^{\circ}, 28.84^{\circ}, 37.72^{\circ}, 42.15^{\circ}, 50.04^{\circ}, 56.20^{\circ}, 60.20^{\circ}, 65.50^{\circ}$, and $69.43^{\circ}$ that correspond to $(110),(200),(220),(310)$, (211), (301), (411), (600), (521), (002), and (541) crystal planes of $\alpha-\mathrm{MnO}_{2}$, respectively (JCPDS: 44-0141). This validates the formation of phase pure tetragonal $\alpha-\mathrm{MnO}_{2}{ }^{38}$ The average crystallite size of the sample is determined to be $13.2 \mathrm{~nm}$ using the Debye-Scherrer method. The profile coefficients and Rietveld refinement of the lattice parameters show agreement between the experimental and a calculated model for the $I 4 / m$ space group. The Rietveld refinement cell parameters resulted in $a=b=9.815 \AA$ and $c=2.847 \AA$, leading to a cell volume of $274.264 \AA^{3}$ for the material. The manganese oxide structure has $1 \mathrm{D}$ voids formed by the corner and edgesharing $\mathrm{MnO}_{6}$ units adopting an $\mathrm{I} 4 / \mathrm{m}$ tetragonal crystal structure (Figure $1 \mathrm{~b}$ ). Among various polymorphs of $\mathrm{MnO}_{2}$, the $\alpha-\mathrm{MnO}_{2}$ tunnel structure is attractive for secondary battery cathode material application. This might be due to that the 1D structure combined with the high oxidation state of electroactive manganese provides an opportunity for (de)insertion of ions. ${ }^{20,39}$ The XPS analysis (Figure $1 \mathrm{c}, \mathrm{d}$ ) showed the spin-orbit doublet of $\mathrm{Mn} 2 \mathrm{p}$ centered at $642.5\left(\mathrm{Mn} \mathrm{2} \mathrm{p}_{3 / 2}\right)$ and $654.0 \mathrm{eV}$ $\left(\mathrm{Mn} 2 \mathrm{p}_{1 / 2}\right)$. The doublet peaks show a separation of $11.5 \mathrm{eV}$, indicating the existence of the $\mathrm{Mn}^{4+}$ oxidation state. ${ }^{40-42}$ The oxygen 1s spectra (Figure 1d) is deconvoluting into two, which indicate the presence of lattice oxygen $\left(\mathrm{O}_{\alpha}, 529.5 \mathrm{eV}\right)$ and defect oxide or the surface oxygen ions $\left(\mathrm{O}_{\beta}, 531.5 \mathrm{eV}\right){ }^{43,44}$ The details of XPS peak deconvolution are as per Note $S 1$ in the Supporting Information.

The FESEM image revealed the morphology of $\alpha-\mathrm{MnO}_{2}$ shown in Figure 2a. It was observed that $\alpha-\mathrm{MnO}_{2}$ consists of nanorods like one-dimensional architectures with an average diameter of $\sim 10 \mathrm{~nm}$ and an average length of $5-10 \mu \mathrm{m}$, as
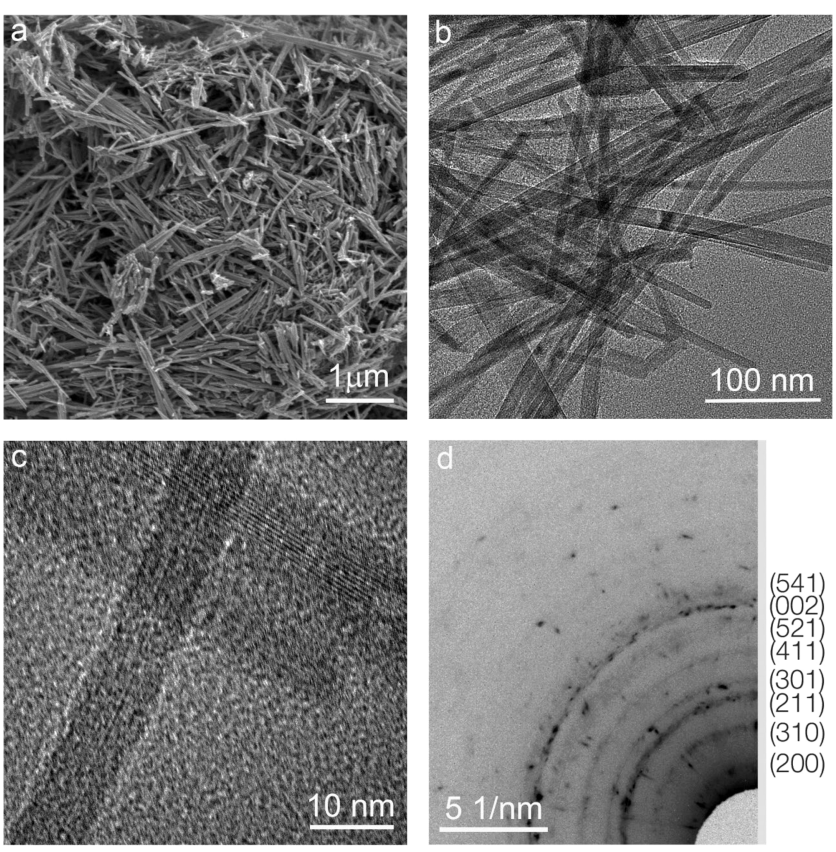

Figure 2. Electron microscopy analysis for the $\mathrm{MnO}_{2}$ nanorods. (a) Panoramic SEM image for the $\mathrm{MnO}_{2}$ sample showing their high degree of homogeneity in the sample. (b) TEM image of nanorods. (c) Lattice-resolved HRTEM image. (d) The bright-field SAED pattern of the $\mathrm{MnO}_{2}$ sample.

confirmed by the TEM analysis of the nanorod (Figure $2 b, c$ ). Besides, SAED patterns demonstrated the coexistence of fine particles and the crystalline nature of $\alpha-\mathrm{MnO}_{2}$ nanorods (Figure $2 \mathrm{~d}$ ). The SAED patterns clearly showed the formation of rings, which can be indexed to the (200), (310), (211), (301), (411), (521), (002), and (541) planes of $\alpha-\mathrm{MnO}_{2}$ (JCPDS: 44-0141). The purity of the samples has been investigated by EDS elemental mapping analysis (Figure S2ac). The presence of $\mathrm{Mn}$ and $\mathrm{O}$ in their optimal stoichiometry indicates the formation of $\alpha-\mathrm{MnO}_{2}$ nanorods without any impurities. These nanorods' unique morphology shows the high surface area for electrolyte ions to penetrate, resulting in enhanced electrochemical performance.

Electrochemical Performance Studies. $\mathrm{Na}^{+}$insertion/ extraction into the $\mathrm{MnO}_{2}$ matrix was evaluated by galvanostatic charge-discharge (GCD) tests within the potential of 1-4 V. To test the mechanism, two electrolyte systems, including $\mathrm{NaPF}_{6}$ in EC:DMC in 5\% FEC and $\mathrm{NaClO}_{4}$ in $\mathrm{PC}$ with $5 \%$ FEC systems, were evaluated for the $\mathrm{MnO}_{2}$ electrodes; the results are shown in Figure 3. Figure 3a,c shows the first discharge curves of the $\mathrm{MnO}_{2}$ electrode at $\mathrm{C} / 20(\mathrm{C} / 20=1 \mathrm{Na}$ in $20 \mathrm{~h}$ ). The discharge curve shows a large voltage plateau up to $1 \mathrm{~V}$, corresponding to $\mathrm{Na}$ ion insertion into the lattice vacancy of $\mathrm{MnO}_{2}$. As seen in Figure 3a, 0.35 sodium can be inserted into $\mathrm{MnO}_{2}$ in the case of using $\mathrm{NaPF}_{6}$ in EC:DMC in $5 \%$ FEC during the first discharge at $\mathrm{C} / 20$ rate between 4 and $1 \mathrm{~V}$ vs $\mathrm{Na}^{+} / \mathrm{Na}$, out of which only 0.29 sodium can be removed on the following charge, leading to reversible operational capacity. In the case of $\mathrm{NaClO}_{4}$ in PC with 5\% FEC electrolyte, there is 0.59 sodiation. An approximate irreversible capacity was $0.06 \mathrm{Na}$ during the first charge for the cutoff voltage of $4 \mathrm{~V}$. As shown in Figure $3 \mathrm{~b}$, for the initial discharge process, the $\mathrm{MnO}_{2}$ electrode achieved a high capacity of 109 $\mathrm{mAh} \cdot \mathrm{g}^{-1}$, with a charge capacity of $\approx 89.3 \mathrm{mAh} \cdot \mathrm{g}^{-1}$ and 

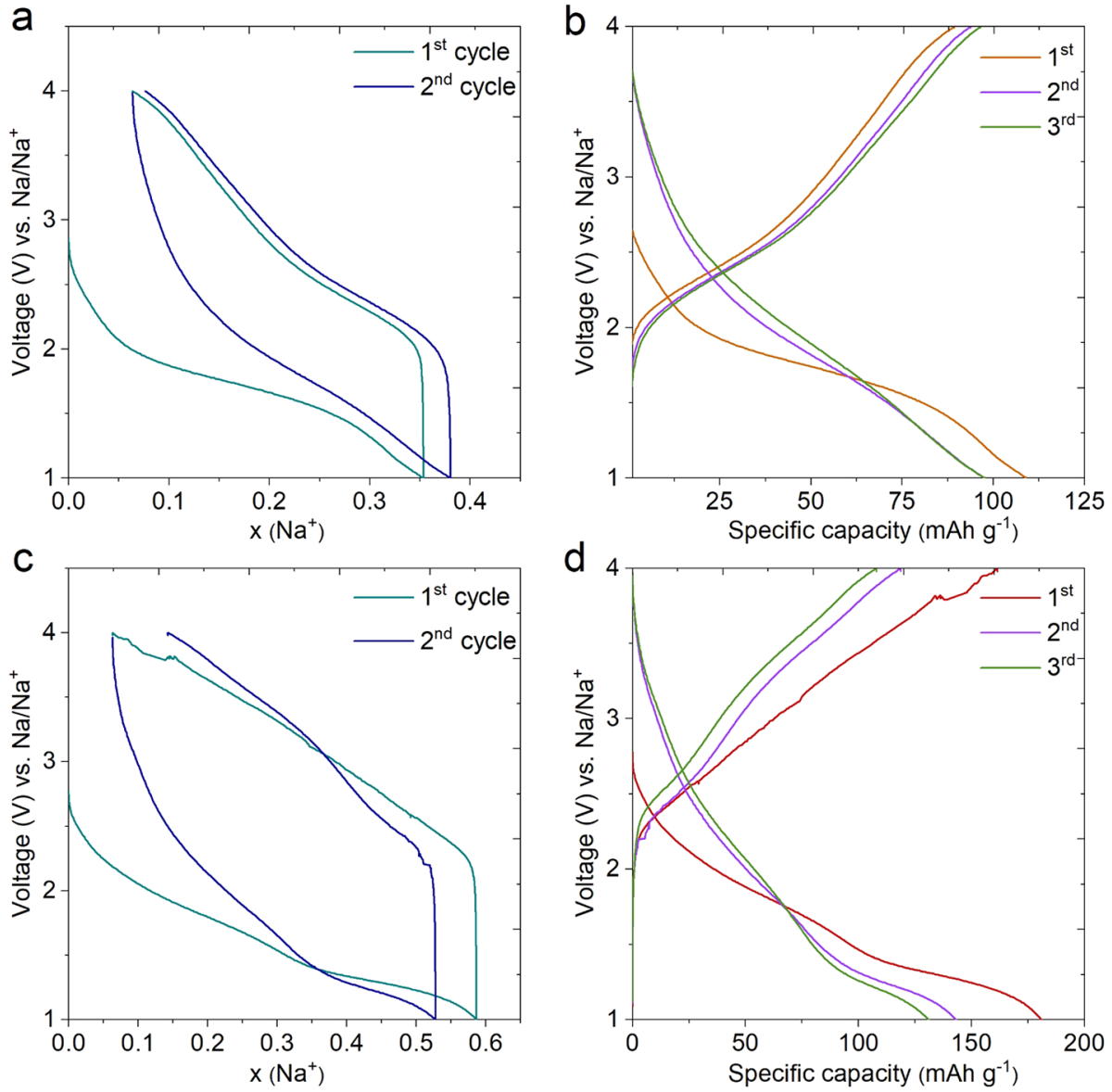

Figure 3. Electrochemical sodium storage capacity of $\mathrm{MnO}_{2}$ nanorods for half sodium cells. (a) Electrochemical charge-discharge curves per $\mathrm{Na}^{+}$ ion, and (b) GCD profiles of $\mathrm{MnO}_{2}$ at C/20 current rate in $\mathrm{NaPF}_{6}$ in EC:DMC in 5\% FEC electrolyte. (c) Comparative charge-discharge curves per $\mathrm{Na}^{+}$ion of the same material in $\mathrm{NaClO}_{4}$ in PC with $5 \%$ FEC electrolyte, and (d) GCD profiles of $\mathrm{MnO}_{2}$ at $\mathrm{C} / 20$ current rate in NaClO $\mathrm{N}_{4}$ in with $5 \%$ FEC electrolyte.

Coulombic efficiency of $81.9 \%$. The remaining discharge and charge capacities were 97.7 and $96.4 \mathrm{mAh} \cdot \mathrm{g}^{-1}$, respectively, after the third cycle. In the case of the $\mathrm{NaClO}_{4} / \mathrm{PC}$ (5\% FEC) electrolyte, $\mathrm{MnO}_{2}$ delivers a discharge and a charge capacity of 181 and $161.5 \mathrm{mAh} \cdot \mathrm{g}^{-1}$, respectively, with a Coulombic efficiency of $89.2 \%$ (Figure 3d). After three cycles, the reserved discharge and charge capabilities were 131.1 and $108 \mathrm{mAh} \cdot \mathrm{g}^{-1}$ with a polarization phenomenon, as observed in the previous one. The improved faradaic kinetics leads to achieving better capacity.

The open channels of $\mathrm{MnO}_{2}$ enable decreased ion diffusion paths and thereby fast electron transfer. The specific capacity observed for the $\mathrm{MnO}_{2}$ electrode in a half-cell is high in the $\mathrm{NaClO}_{4} / \mathrm{PC}$ electrolyte system compared to $\mathrm{NaPF}_{6} / \mathrm{EC}+\mathrm{DEC}$, and it decreases in the following cycles, although the Coulombic efficiency is maintained at $100 \%$ in both electrolytes. Given its excellent electrochemical properties, PC appears to be a promising nonaqueous electrolyte candidate for use in stationary SIBs. ${ }^{45}$

Further, rate performance studies for the $\mathrm{MnO}_{2}$ sample were carried out stepwise from $\mathrm{C} / 20$ to $2 \mathrm{C}$. The observed capacities are $109,89.7,80.6,71.2,62.8$, and $54.9 \mathrm{mAh} \cdot \mathrm{g}^{-1}$ at current rates of $\mathrm{C} / 20, \mathrm{C} / 10, \mathrm{C} / 5, \mathrm{C} / 2, \mathrm{C}$, and $2 \mathrm{C}$, respectively, for $\mathrm{NaPF}_{6}$ electrolyte (Figure 4a). It is worth noting (Figure $4 \mathrm{~b}$ ) that the specific capacity nearly recovered the initial value of $88.3 \mathrm{mAh} \cdot \mathrm{g}^{-1}$ along with the Coulombic efficiency of $100 \%$ at the reverse current rate of $\mathrm{C} / 20$, indicating the excellent structural stability and reversibility of the $\mathrm{MnO}_{2}$ sample. $\mathrm{MnO}_{2}$ showed a discharge capacity of $181,85.5,54.8,35.6,20.7$, and $7.3 \mathrm{mAh} \cdot \mathrm{g}^{-1}$ at current rates of $\mathrm{C} / 20, \mathrm{C} / 10, \mathrm{C} / 5, \mathrm{C} / 2, \mathrm{C}$, and $2 \mathrm{C}$, respectively, in $\mathrm{NaClO}_{4}$ electrolyte, which is much better as compared to the results in $\mathrm{NaPF}_{6}$ electrolyte (Figure 4c). The high capacitance of the $\mathrm{MnO}_{2}$ electrode in $\mathrm{PC}$ compared to $\mathrm{EC}+\mathrm{DMC}$ is derived from ion diffusivity, improved conductivity, and porous conductive matrix engagement. There is no apparent capacity fading tendency for the case of $\mathrm{NaPF}_{6}$ in $\mathrm{EC}+\mathrm{DMC}$ electrolyte; however, $\mathrm{MnO}_{2}$ displayed severe capacity degeneration in $\mathrm{NaClO}_{4}$ in $\mathrm{PC}$ as shown in rate capability studies (Figure 4d). $\mathrm{MnO}_{2}$ exhibited poor cycle stability at the high current density and stable performance at low current density.

The extended cycling tests of the $\mathrm{MnO}_{2}$ electrodes in the $\mathrm{NaPF}_{6} / \mathrm{EC}+\mathrm{DMC}$ and $\mathrm{NaClO}_{4} / \mathrm{PC}$ electrolytes are as shown in Figure 5a,b. The capacity retention of $58.6 \%$ after 800 cycles can be observed in $\mathrm{NaPF}_{6} / \mathrm{EC}+\mathrm{DMC}$ electrolyte at the current rate of $1 \mathrm{C}$, whereas, for the $\mathrm{NaClO}_{4} / \mathrm{PC}$ electrolyte, a severe capacity fading was observed after the first cycle and retained only $11.5 \%$ after 800 cycles. This might be due to large polarization on the $\mathrm{MnO}_{2}$ surface due to decomposition of PC. ${ }^{46}$ Although, it is reported that the EC+DMC-based electrolyte is reactive against $\mathrm{Na}$ and unsuitable for SIBs. ${ }^{47}$ The $\mathrm{NaPF}_{6} / \mathrm{EC}+\mathrm{DMC}$ electrolyte shows better electrochemical performance in terms of excellent stability with a moderate capacity of $\mathrm{MnO}_{2}$ than the $\mathrm{NaClO}_{4} / \mathrm{PC}$ electrolyte. The 

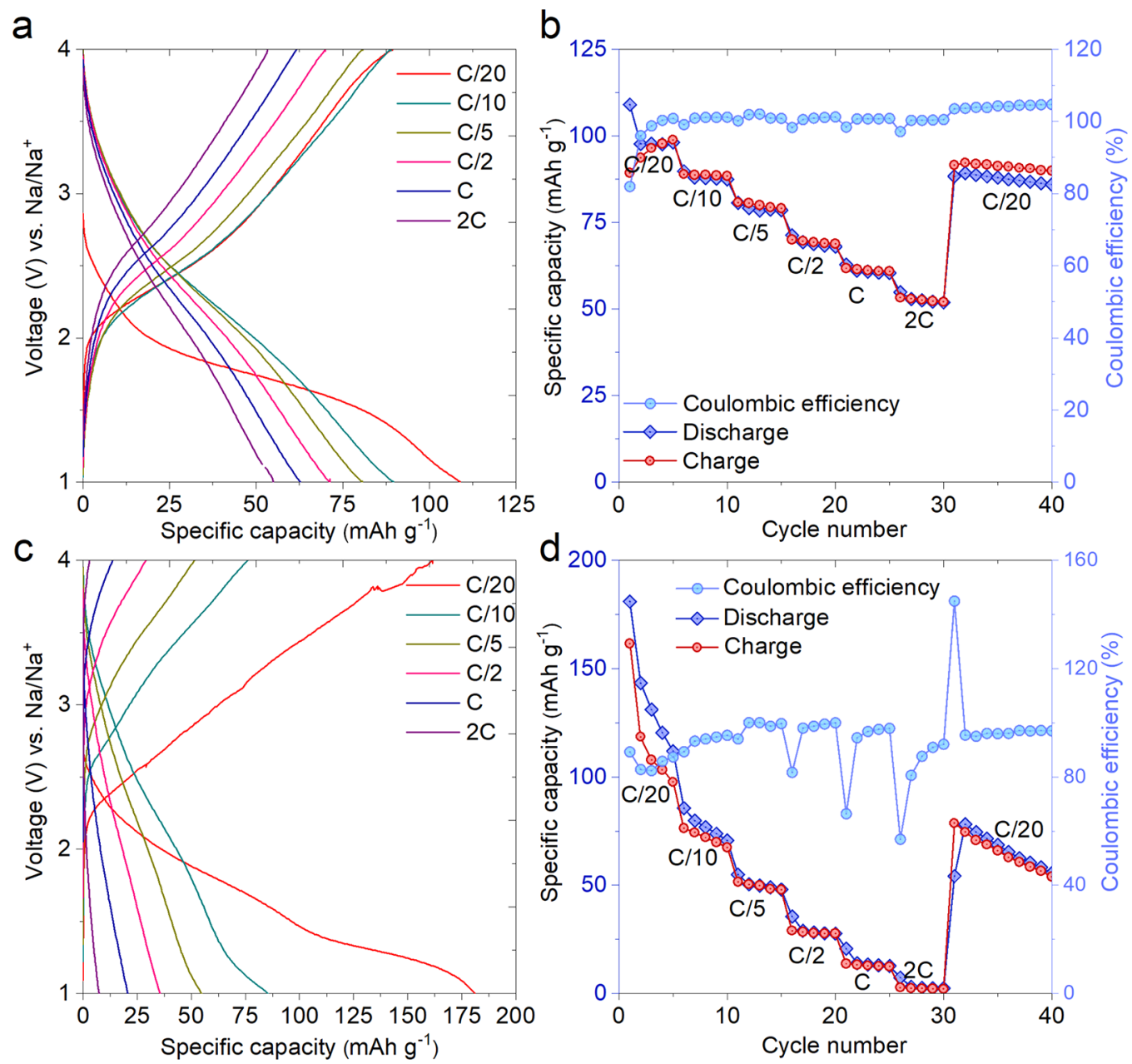

Figure 4. Comparative studies for different electrolytes. (a) GCD profiles of $\mathrm{MnO}_{2}$ cathode at different C-rates, for $\mathrm{C} / 20$ to $2 \mathrm{C}$ rates in $\mathrm{NaPF}_{6}$ in EC:DMC in 5\% FEC, and (b) rate capability at varying C-rates and corresponding Coulombic efficiencies in NaPF 6 in EC:DMC in 5\% FEC. Furthermore, studies have been carried out for (c) GCD profiles of $\mathrm{MnO}_{2}$ cathode at different C-rates, for C/20 to $2 \mathrm{C}$ rates in $\mathrm{NaClO}_{4}$ in $\mathrm{PC}$ with $5 \%$ FEC electrolyte, and (d) rate capability at varying C-rates and corresponding Coulombic efficiencies in $\mathrm{NaClO}_{4}$ in $\mathrm{PC}$ with $5 \% \mathrm{FEC}$ electrolyte.

stability reported by this study is much higher than the other literature reports of $\mathrm{MnO}_{2}$ for SIBs (Table S1).

Electrochemical impedance spectra (EIS) were investigated to gain insights into the reaction kinetics and the charge transfer. Figure 5c illustrates the EIS measurements of $\mathrm{MnO}_{2}$ for both the electrolytes. The well fitted equivalent circuit model for the same is as shown in Figure S3. The internal resistance $\left(R_{\mathrm{s}}\right)$ corresponds to the intersection point on the $X$ axis, whereas the charge transfer resistance $\left(R_{\mathrm{CT}}\right)$ is denoted by the semicircular arc in the high frequency region. ${ }^{4-51}$ The constant phase element (CPE) and Warburg resistance $(W)$ are associated with the double layer component inside pores and diffusion in the $\mathrm{MnO}_{2}$ nanostructure. ${ }^{52,53}$ The $R_{\mathrm{L}}$ component associates with lekage resistance during electrochemical activities. It is observed that the obtained value of $R_{\mathrm{CT}}$ for $\mathrm{NaClO}_{4} / \mathrm{PC}$ is $43.4 \Omega$ (Figure $5 \mathrm{c}$ ), which is smaller than that of $\mathrm{NaPF}_{6} / \mathrm{EC}+\mathrm{DMC}(46.1 \Omega)$ as presented in Table S2, suggesting slightly improved charge transfer speed and fast $\mathrm{Na}^{+}$ions diffusion through the electrode-electrolyte interface. As shown in the Bode plot (Figure 5d), the $\mathrm{MnO}_{2}$ nanorods electrodes' slope values at the high- $(<1)$ and low-frequency $(\sim 0)$ regions suggest that $\mathrm{MnO}_{2}$ has a faster sodium ion diffusion rate. ${ }^{54,55}$
DFT Studies. Further insights into the electronic structure and $\mathrm{Na}$ ion diffusion in $\alpha-\mathrm{MnO}_{2}$ were gained through firstprinciples DFT calculations. Both the pristine and $\mathrm{Na}$ ions intercalated $\alpha-\mathrm{MnO}_{2}$ were modeled as a tetragonal crystal structure with an antiferromagnetic spin configuration, as shown in Figure 6a,b. A full unit cell relaxation yielded a strainfree $\alpha-\mathrm{MnO}_{2}$ with lattice parameters $a=b=9.763 \AA, c=2.872$ $\AA$, in good agreement with the experimental data in the present and previous studies. ${ }^{56,57}$ The $\mathrm{Na}$ ion intercalation maintained the tetragonal structure with only slight contraction $(1.53 \%)$ of the unit cell volume, the lattice parameters predicted at $a=b=$ $9.715 \AA$ and $c=2.856 \AA$. The predicted electronic band gap of pristine $\alpha-\mathrm{MnO}_{2}$ is $2.42 \mathrm{eV}$ (Figure 6c), and the experimental value of $2.23 \mathrm{eV}$ is in good agreement. ${ }^{58}$ The valence band edge of $\mathrm{MnO}_{2}$ consists mainly of $\mathrm{O} p$ states, whereas $\mathrm{Mnd}$ states dominate the conduction band edge. Adding one $\mathrm{Na}$ atom puts one additional electron into the system, which caused a shift of the Fermi level near the conduction band (CB) edge and a reduction in the band gap to $2.01 \mathrm{eV}$. The charges on the $\mathrm{O}$ atoms located in the one-dimensional tunnel close to the $\mathrm{Na}$ ions have increased. Bader population analysis (Table S3) shows that the four oxygens closest to the $\mathrm{Na}$ ion received additional charges of $0.2 \mathrm{e}^{-}$each. The charge density 

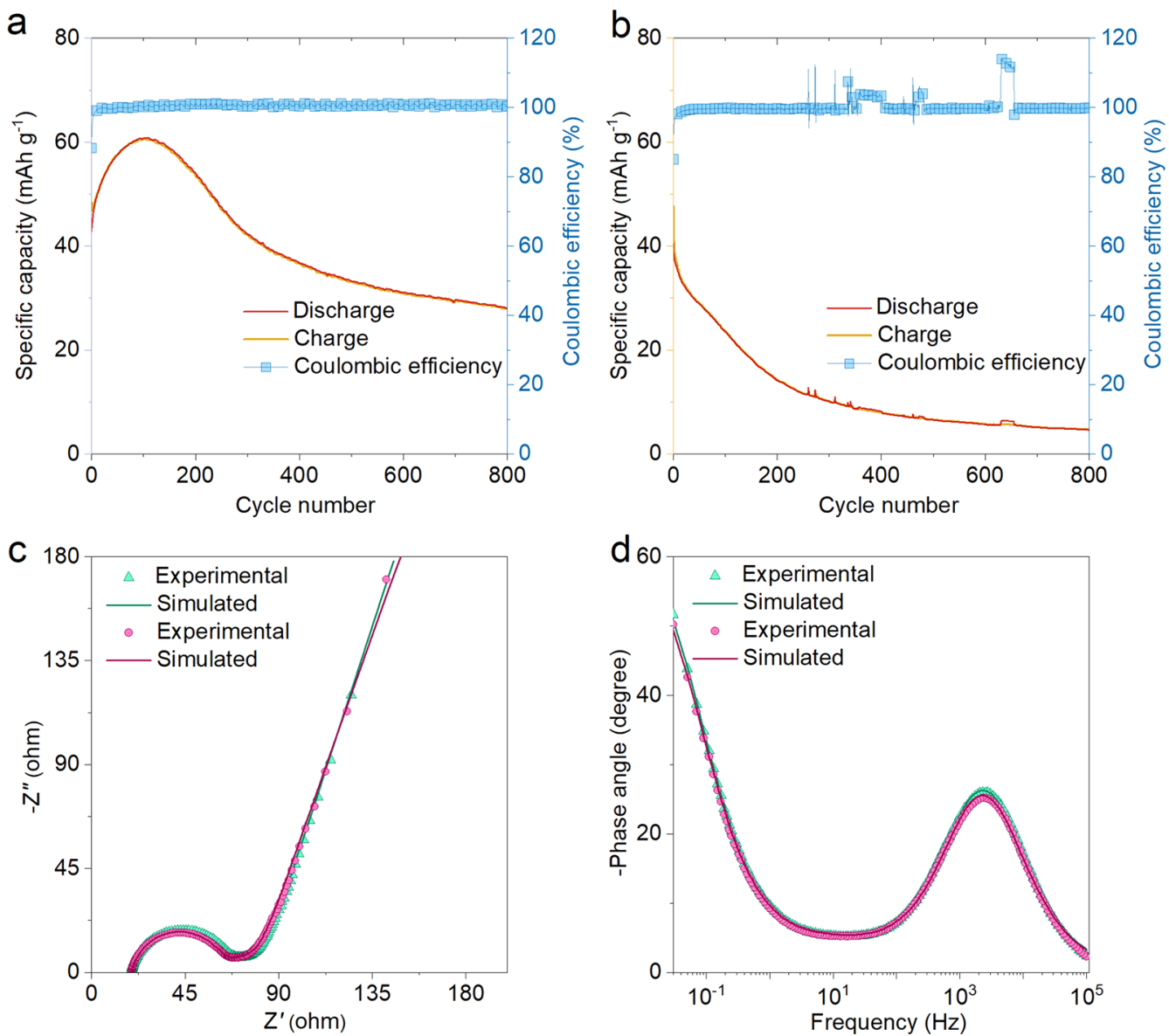

Figure 5. Extended cycling performance studies. (a) Extended cycling performance and the corresponding Coulombic efficiency at 1C-rate showing $\sim 58.6 \%$ of capacity retention and is maintained after 800 cycles in $\mathrm{NaPF}_{6}$ in EC:DMC in $5 \%$ FEC. (b) The comparative stability test of the same sample in $\mathrm{NaClO}_{4}$ in PC with 5\% FEC electrolyte shows that capacity decreases abruptly after 200 cycles; this is a consequence of large polarization on the $\mathrm{MnO}_{2}$ surface due to the decomposition of PC during the charging process. (c) The Nyquist plots and (d) Bode plots for corresponding $\mathrm{NaPF}_{6}$ in EC:DMC in $5 \% \mathrm{FEC}$ (violet in color) and $\mathrm{NaClO}_{4}$ in $\mathrm{PC}$ with $5 \% \mathrm{FEC}$ (green in color) electrolytes.
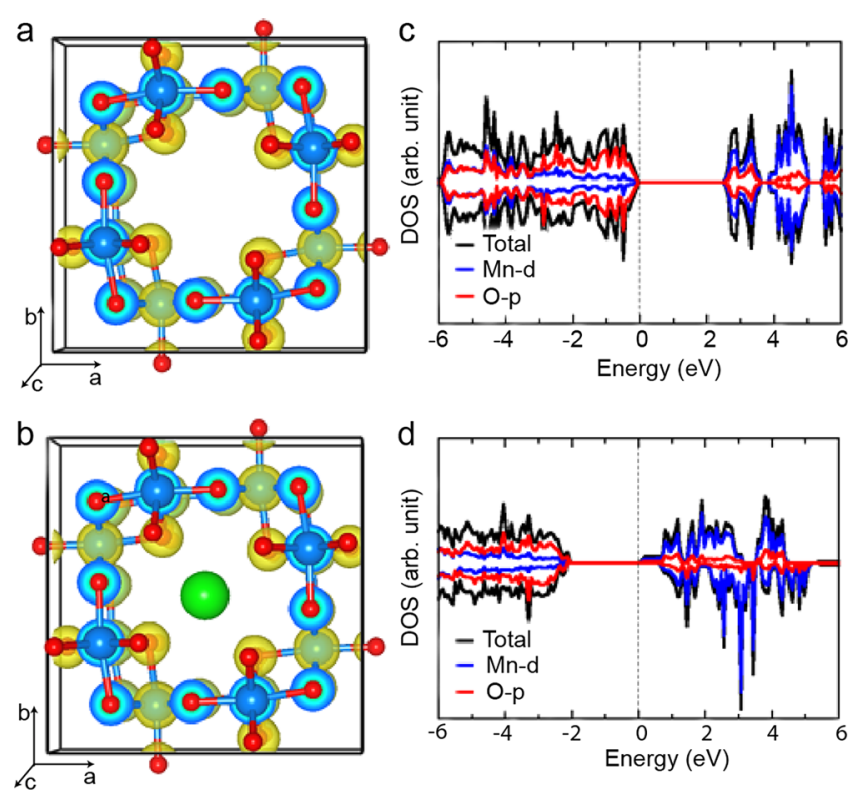

Figure 6. Charge density distribution for (a) pristine and (b) Naintercalated $\alpha-\mathrm{MnO}_{2}$. (c) Total (black line) and projected DOS on $\mathrm{Mn}$ ions (blue line) and $\mathrm{O}$ ions (red line) in pristine and (d) Naintercalated $\alpha-\mathrm{MnO}_{2}$. in the pristine $\alpha-\mathrm{MnO}_{2}$ and $\mathrm{Na}$-intercalated $\alpha-\mathrm{MnO}_{2}$ systems is shown in Figure 6a,b.

The voltage produced by the electrochemical process of $\mathrm{Na}$ $+\mathrm{MnO}_{2} \rightarrow \mathrm{NaMnO}_{2}$ was determined based on the following energy difference $V=-\left(\frac{E\left(\mathrm{NaMnO}_{2}\right)-E\left(\mathrm{MnO}_{2}\right)-E(\mathrm{Na})}{N_{\text {electrons }}}\right)$, where $E\left(\mathrm{NaMnO}_{2}\right)$ is the energy of the $\alpha-\mathrm{MnO}_{2}$ intercalated with a $\mathrm{Na}$ ion, $E\left(\mathrm{MnO}_{2}\right)$ is the energy of the pristine $\alpha-\mathrm{MnO}_{2}, E(\mathrm{Na})$ is the energy a $\mathrm{Na}$ atom, and $N_{\text {electrons }}$ is the number of electrons transferred with the cation. ${ }^{59}$ Volume and entropy effects are not included considering they are typically negligible $(\leq 0.1 \mathrm{~V}){ }^{60}$ The reaction of $\mathrm{Na}$ with $\alpha-\mathrm{MnO}_{2}$ produced a voltage of $3.42 \mathrm{~V}$, similar to the earlier reported voltage of 3.23 $\mathrm{V}$ by Tompsett et al. ${ }^{61}$ The kinetics of $\mathrm{Na}$ diffusing in the $\alpha$ $\mathrm{MnO}_{2}$ was evaluated performing a climbing-image nudge elastic band (CI-NEB) calculation, where seven images were constructed for interpolating the $\mathrm{Na}$ diffusion path along the 1D tunnel within the $1 \times 1 \times 2 \alpha-\mathrm{MnO}_{2}$ as shown in Figure S4. The calculated migration energy barrier of $\mathrm{Na}$ was $0.21 \mathrm{eV}$, which is relatively low for practical battery applications. ${ }^{62}$ This is consistent with previous theoretical predictions by Tompsett et al., who reported the migration barriers for both $\mathrm{Li}$ ions and $\mathrm{Na}$ ions to be less than $0.3 \mathrm{eV} .^{61}$ 


\section{CONCLUSIONS}

In summary, $\alpha-\mathrm{MnO}_{2}$ nanorods prepared using a hydrothermal method exhibited impressive electrochemical performance as a cathode material for SIBs when charged and discharged in the voltage range of $1-4 \mathrm{~V}$, rendering an initial discharge capacity of $181 \mathrm{mAh} \cdot \mathrm{g}^{-1}$ at $\mathrm{C} / 20$, however, with low capacity retention in $\mathrm{NaClO}_{4} / \mathrm{PC}$ electrolyte. In comparison, the cycling performance is improved (58.6\% after 800 cycles) when using $\mathrm{NaPF}_{6} / \mathrm{EC}+\mathrm{DMC}$ electrolyte, though it suffers from less capacity $\left(109 \mathrm{mAh} \cdot \mathrm{g}^{-1}\right)$. Furthermore, the discharge capacities changed when cycled at different rates. Such superior electrochemical performance of the $\alpha-\mathrm{MnO}_{2}$ material utilized in SIBs promises to solve stability issues. The $\alpha-\mathrm{MnO}_{2}$ displays a high voltage of $3.42 \mathrm{~V}$ for $\mathrm{Na}$ intercalation and facile diffusion kinetics with a diffusion barrier as low as $0.21 \mathrm{eV}$ as predicted from first-principles DFT calculations. The experimental results suggest that the hierarchically organized $\alpha-\mathrm{MnO}_{2}$ sufficiently satisfies the stringent requirements of electrode materials in constructing high-power and long-term life batteries for energy storage applications. Further, we expect that novel efforts in finding newer electrolytes and their additives will overcome the present hurdles in achieving higher energy density with stable cycle performance for SIB.

\section{EXPERIMENTAL SECTION}

Synthesis of $\mathrm{MnO}_{2}$ Nanorods. The chemical oxidation of a manganese precursor (manganese(II) acetate) with ammonium persulfate in alkaline conditions leads to $\mathrm{MnO}_{2}$ synthesis. First, sodium hydroxide $(100 \mathrm{~mL})$ of desired concentration was prepared. This transparent solution of sodium hydroxide is taken in two separate beakers: one for ammonium persulfate precursor and the other for manganese precursor. After stirring the two solutions separately, the beaker containing ammonium persulfate solution is slowly poured into the manganese precursor solution. This solution is transferred into a Teflon-lined stainless-steel autoclave. This solution is kept at $180^{\circ} \mathrm{C}$ for $14 \mathrm{~h}$. The resultant precipitate was washed with ethanol and water and dried at $60^{\circ} \mathrm{C}$ for $12 \mathrm{~h}$. Finally, this product is annealed at $300{ }^{\circ} \mathrm{C}$ in the air atmosphere for $4 \mathrm{~h}$. The chemical reactions involved in the formation of manganese dioxide are as per previous reports. ${ }^{13}$

Material Characterization. An X-ray diffractometer (XRD) was used to identify the phase of the prepared $\mathrm{MnO}_{2}$ powder using the $\mathrm{D} 8$ Advance Bruker instrument using monochromatic $\mathrm{Cu} \mathrm{K} \alpha$ radiation $(\lambda$ $=1.5406 \AA$ ). X-ray Rietveld refinement was carried out with the FullProf program using the pseudo-Voigt profile function. Raman studies were performed with a LabRAM HR, $532 \mathrm{~nm}$ laser excitation. $\mathrm{X}$-ray photoelectron spectroscopy (XPS) analysis was carried out for the samples, using an ESCALAB 250 (ThermoElectron, $\mathrm{Al} \mathrm{K \alpha}$ ) spectrometer. The electron microscopy analysis was carried out using a field emission scanning electron microscope (Hitachi S-4800) and a high-resolution transmission electron microscope (TECNAI G2 20 Twin, FEI). The details about electrochemical analysis and firstprinciples calculations are as per Note S2.

\section{ASSOCIATED CONTENT}

\section{SI Supporting Information}

The Supporting Information is available free of charge at https://pubs.acs.org/doi/10.1021/acsami.0c21081.

Details of XPS peak deconvolution, details of electrochemical and computational analysis, Raman spectrum, EDS elemental analysis, equivalent circuit for EIS spectra, energy profile of $\mathrm{Na}$ ion migration path through the $\alpha-\mathrm{MnO}_{2}$, table of comparative performance for cycle life, equivalent circuit parameters, Bader charge analysis results of pristine and $\mathrm{Na}$-intercalated $\alpha-\mathrm{MnO}_{2}$ (PDF)

\section{AUTHOR INFORMATION}

\section{Corresponding Authors}

Bidhan Pandit - Institut Charles Gerhardt Montpellier (ICGM), Université de Montpellier, Montpellier 34095, France; Department of Materials Science and Engineering and Chemical Engineering, Universidad Carlos III de Madrid, E-28911 Leganés, Madrid, Spain; orcid.org/ 0000-0003-4656-9289; Email: physics.bidhan@gmail.com

Rahul R. Salunkhe - Department of Physics, Indian Institute of Technology Jammu Jagti, Jammu 181221, J \& K, India; Email: rahul.salunkhe@iitjammu.ac.in

\section{Authors}

Sachin R. Rondiya - School of Chemistry, Cardiff University, Cardiff CF10 3AT, Wales, United Kingdom; (o orcid.org/ 0000-0003-1350-1237

Nelson Y. Dzade - School of Chemistry, Cardiff University, Cardiff CF10 3AT, Wales, United Kingdom; (1) orcid.org/ 0000-0001-7733-9473

Shoyebmohamad F. Shaikh - Department of Chemistry, College of Science, King Saud University, Riyadh 11451, Saudi Arabia

Nitish Kumar - Department of Physics, Indian Institute of Technology Jammu Jagti, Jammu 181221, J \& K, India

Emad S. Goda - Fire Protection Laboratory, National Institute of Standards, Giza 12211, Egypt

Abdullah A. Al-Kahtani - Department of Chemistry, College of Science, King Saud University, Riyadh 11451, Saudi Arabia

Rajaram S. Mane - Swami Ramanand Teerth Marathwada University, Nanded 431606, M.S., India

Sanjay Mathur - Chemistry Department, Institute of Inorganic Chemistry, University of Cologne, 50939 Cologne, Germany; (1) orcid.org/0000-0003-2765-2693

Complete contact information is available at:

https://pubs.acs.org/10.1021/acsami.0c21081

\section{Author Contributions}

All authors have approved the final version of the manuscript.

Notes

The authors declare no competing financial interest.

\section{ACKNOWLEDGMENTS}

B.P. acknowledges the support from CONEX-Plus programme (No. 801538) funded by Universidad Carlos III de Madrid and the European Commission. S.R.R. and N.Y.D. acknowledge the UK Engineering and Physical Sciences Research Council (EPSRC) for funding (Grant No. EP/S001395/1). The computational resources used are the Advanced Research Computing at Cardiff (ARCCA) Division, Cardiff University, and HPC Wales and ARCHER (http://www.archer.ac.uk), the UK's national supercomputing service, via the membership of the UK's HEC Materials Chemistry Consortium, which is funded by EPSRC (EP/L000202). The authors thank the Researchers Supporting Project (RSP-2020/266), King Saud University, Riyadh, Saudi Arabia, for financial support. S.M. is thankful to the University of Cologne for financial and infrastructural support. R.R.S. is thankful for the SERB funding support (SB/S2/RJN-023/2017 and CRG/2020/003199) and IIT Jammu SEED grants (SG0008). Information on the data that underpins the results presented here, including how to 
access them, can be found in the Cardiff University data catalogue at http://doi.org/10.17035/d.2021.0128995615.

\section{REFERENCES}

(1) Choi, J. W.; Aurbach, D. Promise and Reality of Post-LithiumIon Batteries with High Energy Densities. Nat. Rev. Mater. 2016, 1, 16013.

(2) Lee, J.; Moon, J.; Han, S. A.; Kim, J.; Malgras, V.; Heo, Y.-U.; Kim, H.; Lee, S.-M.; Liu, H. K.; Dou, S. X.; Yamauchi, Y.; Park, M.-S.; Kim, J. H. Everlasting Living and Breathing Gyroid 3D Network in $\mathrm{Si} @ \mathrm{SiO}_{\mathrm{x}} / \mathrm{C}$ Nanoarchitecture for Lithium Ion Battery. ACS Nano 2019, 13, 9607-9619.

(3) Hwang, S. M.; Lim, Y.-G.; Kim, J.-G.; Heo, Y.-U.; Lim, J. H.; Yamauchi, Y.; Park, M.-S.; Kim, Y.-J.; Dou, S. X.; Kim, J. H. A Case Study on Fibrous Porous $\mathrm{SnO}_{2}$ Anode for Robust, High-Capacity Lithium-Ion Batteries. Nano Energy 2014, 10, 53-62.

(4) Hwang, S. M.; Kim, S. Y.; Kim, J.-G.; Kim, K. J.; Lee, J.-W.; Park, M.-S.; Kim, Y.-J.; Shahabuddin, M.; Yamauchi, Y.; Kim, J. H. Electrospun Manganese-Cobalt Oxide Hollow Nanofibres Synthesized via Combustion Reactions and Their Lithium Storage Performance. Nanoscale 2015, 7, 8351-8355.

(5) Xue, H.; Zhao, J.; Tang, J.; Gong, H.; He, P.; Zhou, H.; Yamauchi, Y.; He, J. High-Loading Nano-SnO ${ }_{2}$ Encapsulated in Situ in Three-Dimensional Rigid Porous Carbon for Superior Lithium-Ion Batteries. Chem. - Eur. J. 2016, 22, 4915-4923.

(6) Xu, W.; Wang, J.; Ding, F.; Chen, X.; Nasybulin, E.; Zhang, Y.; Zhang, J.-G. Lithium Metal Anodes for Rechargeable Batteries. Energy Environ. Sci. 2014, 7, 513-537.

(7) Goodenough, J. B.; Park, K.-S. The Li-Ion Rechargeable Battery: A Perspective. J. Am. Chem. Soc. 2013, 135, 1167-1176.

(8) Kim, T.-H.; Park, J.-S.; Chang, S. K.; Choi, S.; Ryu, J. H.; Song, H.-K. The Current Move of Lithium Ion Batteries Towards the Next Phase. Adv. Energy Mater. 2012, 2, 860-872.

(9) Nayak, P. K.; Yang, L.; Brehm, W.; Adelhelm, P. From LithiumIon to Sodium-Ion Batteries: Advantages, Challenges, and Surprises. Angew. Chem., Int. Ed. 2018, 57, 102-120.

(10) Nithya, C.; Gopukumar, S. Sodium Ion Batteries: A Newer Electrochemical Storage. Wiley Interdiscip. Rev. Energy Environ. 2015, 4, 253-278.

(11) Dunn, B.; Kamath, H.; Tarascon, J.-M. Electrical Energy Storage for the Grid: A Battery of Choices. Science 2011, 334, 928935.

(12) Hwang, J.-Y.; Kim, H. M.; Sun, Y.-K. High Performance Potassium-Sulfur Batteries Based on a Sulfurized Polyacrylonitrile Cathode and Polyacrylic Acid Binder. J. Mater. Chem. A 2018, 6, 14587-14593.

(13) Shiva, K.; Singh, P.; Zhou, W.; Goodenough, J. B. $\mathrm{NaFe}_{2} \mathrm{PO}_{4}\left(\mathrm{SO}_{4}\right)_{2}$ : A Potential Cathode for a Na-Ion Battery. Energy Environ. Sci. 2016, 9, 3103-3106.

(14) Fang, Y.; Zhang, J.; Xiao, L.; Ai, X.; Cao, Y.; Yang, H. Phosphate Framework Electrode Materials for Sodium Ion Batteries. Adv. Sci. 2017, 4, 1600392.

(15) Li, M.; Lu, J.; Ji, X.; Li, Y.; Shao, Y.; Chen, Z.; Zhong, C.; Amine, K. Design Strategies for Nonaqueous Multivalent-Ion and Monovalent-Ion Battery Anodes. Nat. Rev. Mater. 2020, 5, 276-294.

(16) Lee, J.; Kitchaev, D. A.; Kwon, D.-H.; Lee, C.-W.; Papp, J. K.; Liu, Y.-S.; Lun, Z.; Clément, R. J.; Shi, T.; McCloskey, B. D.; Guo, J.; Balasubramanian, M.; Ceder, G. Reversible $\mathrm{Mn}^{2+} / \mathrm{Mn}^{4+}$ Double Redox in Lithium-Excess Cathode Materials. Nature 2018, 556, 185190.

(17) Su, H.; Jaffer, S.; Yu, H. Transition Metal Oxides for SodiumIon Batteries. Energy Storage Mater. 2016, 5, 116-131.

(18) Cao, Y.; Xiao, L.; Wang, W.; Choi, D.; Nie, Z.; Yu, J.; Saraf, L. V.; Yang, Z.; Liu, J. Reversible Sodium Ion Insertion in Single Crystalline Manganese Oxide Nanowires with Long Cycle Life. Adv. Mater. 2011, 23, 3155-3160.

(19) Li, Z.; Young, D.; Xiang, K.; Carter, W. C.; Chiang, Y.-M. Towards High Power High Energy Aqueous Sodium-Ion Batteries:
The $\mathrm{NaTi}_{2}\left(\mathrm{PO}_{4}\right)_{3} / \mathrm{Na}_{0.44} \mathrm{MnO}_{2}$ System. Adv. Energy Mater. 2013, 3, 290-294.

(20) Su, D.; Ahn, H.-J.; Wang, G. Hydrothermal Synthesis of $\alpha$ $\mathrm{MnO}_{2}$ and $\beta-\mathrm{MnO}_{2}$ Nanorods as High Capacity Cathode Materials for Sodium Ion Batteries. J. Mater. Chem. A 2013, 1, 4845.

(21) Caballero, A.; Hernán, L.; Morales, J.; Sánchez, L.; Santos Peña, J.; Aranda, M. A. G. Synthesis and Characterization of HighTemperature Hexagonal $\mathrm{P} 2-\mathrm{Na}_{0.6} \mathrm{MnO}_{2}$ and Its Electrochemical Behaviour as Cathode in Sodium Cells. J. Mater. Chem. 2002, 12, $1142-1147$.

(22) Zhu, H.; Lee, K. T.; Hitz, G. T.; Han, X.; Li, Y.; Wan, J.; Lacey, S.; Cresce, A. V. W.; Xu, K.; Wachsman, E.; Hu, L. Free-Standing $\mathrm{Na}_{2 / 3} \mathrm{Fe}_{1 / 2} \mathrm{Mn}_{1 / 2} \mathrm{O}_{2} @$ Graphene Film for a Sodium-Ion Battery Cathode. ACS Appl. Mater. Interfaces 2014, 6, 4242-4247.

(23) Lee, B.; Yoon, C. S.; Lee, H. R.; Chung, K. Y.; Cho, B. W.; Oh, S. H. Electrochemically-Induced Reversible Transition from the Tunneled to Layered Polymorphs of Manganese Dioxide. Sci. Rep. 2015, 4, 6066.

(24) Monti, D.; Jónsson, E.; Palacín, M. R.; Johansson, P. Ionic Liquid Based Electrolytes for Sodium-Ion Batteries: Na+ Solvation and Ionic Conductivity. J. Power Sources 2014, 245, 630-636.

(25) Dai, Z.; Mani, U.; Tan, H. T.; Yan, Q. Advanced Cathode Materials for Sodium-Ion Batteries: What Determines Our Choices? Small Methods 2017, 1, 1700098.

(26) Che, H.; Chen, S.; Xie, Y.; Wang, H.; Amine, K.; Liao, X.-Z.; Ma, Z.-F. Electrolyte Design Strategies and Research Progress for Room-Temperature Sodium-Ion Batteries. Energy Environ. Sci. 2017, 10, 1075-1101.

(27) Bommier, C.; Ji, X. Electrolytes, SEI Formation, and Binders: A Review of Nonelectrode Factors for Sodium-Ion Battery Anodes. Small 2018, 14, 1703576.

(28) Ponrouch, A.; Monti, D.; Boschin, A.; Steen, B.; Johansson, P.; Palacín, M. R. Non-Aqueous Electrolytes for Sodium-Ion Batteries. J. Mater. Chem. A 2015, 3, 22-42.

(29) Wang, J.; Zhang, Q.; Li, X.; Xu, D.; Wang, Z.; Guo, H.; Zhang, K. Three-Dimensional Hierarchical $\mathrm{Co}_{3} \mathrm{O}_{4} / \mathrm{CuO}$ Nanowire Heterostructure Arrays on Nickel Foam for High-Performance Lithium Ion Batteries. Nano Energy 2014, 6, 19-26.

(30) Tang, W.-J.; Peng, W.-J.; Yan, G.-C.; Guo, H.-J.; Li, X.-H.; Zhou, Y. Effect of Fluoroethylene Carbonate as an Electrolyte Additive on the Cycle Performance of Silicon-Carbon Composite Anode in Lithium-Ion Battery. Ionics 2017, 23, 3281-3288.

(31) Komaba, S.; Ishikawa, T.; Yabuuchi, N.; Murata, W.; Ito, A.; Ohsawa, Y. Fluorinated Ethylene Carbonate as Electrolyte Additive for Rechargeable Na Batteries. ACS Appl. Mater. Interfaces 2011, 3, 4165-4168.

(32) Webb, S. A.; Baggetto, L.; Bridges, C. A.; Veith, G. M. The Electrochemical Reactions of Pure Indium with $\mathrm{Li}$ and $\mathrm{Na}$ : Anomalous Electrolyte Decomposition, Benefits of FEC Additive, Phase Transitions and Electrode Performance. J. Power Sources 2014, 248, 1105-1117.

(33) Ponrouch, A.; Goñi, A. R.; Palacín, M. R. High Capacity Hard Carbon Anodes for Sodium Ion Batteries in Additive Free Electrolyte. Electrochem. Commun. 2013, 27, 85-88.

(34) Dugas, R.; Ponrouch, A.; Gachot, G.; David, R.; Palacin, M. R.; Tarascon, J. M. Na Reactivity toward Carbonate-Based Electrolytes: The Effect of FEC as Additive. J. Electrochem. Soc. 2016, 163, A2333A2339.

(35) Bai, P.; Han, X.; He, Y.; Xiong, P.; Zhao, Y.; Sun, J.; Xu, Y. Solid Electrolyte Interphase Manipulation towards Highly Stable Hard Carbon Anodes for Sodium Ion Batteries. Energy Storage Mater. 2020, 25, 324-333.

(36) Zhang, B.; Cheng, G.; Lan, B.; Zheng, X.; Sun, M.; Ye, F.; Yu, L.; Cheng, X. Crystallization Design of $\mathrm{MnO}_{2}$ via Acid towards Better Oxygen Reduction Activity. CrystEngComm 2016, 18, 6895-6902.

(37) Cheng, S.; Yang, L.; Chen, D.; Ji, X.; Jiang, Z.; Ding, D.; Liu, M. Phase Evolution of an Alpha $\mathrm{MnO}_{2}$-Based Electrode for PseudoCapacitors Probed by in Operando Raman Spectroscopy. Nano Energy 2014, 9, 161-167. 
(38) Sun, L.; Li, N.; Zhang, S.; Yu, X.; Liu, C.; Zhou, Y.; Han, S.; Wang, W.; Wang, Z. Nitrogen-Containing Porous Carbon $/ \alpha-\mathrm{MnO}_{2}$ Nanowires Composite Electrode towards Supercapacitor Applications. J. Alloys Compd. 2019, 789, 910-918.

(39) $\mathrm{Su}, \mathrm{D}$.; Ahn, H.-J.; Wang, G. $\beta-\mathrm{MnO}_{2}$ Nanorods with Exposed Tunnel Structures as High-Performance Cathode Materials for Sodium-Ion Batteries. NPG Asia Mater. 2013, 5, e70-e70.

(40) Yu, C.; Li, G.; Wei, L.; Fan, Q.; Shu, Q.; Yu, J. C. Fabrication, Characterization of $\beta-\mathrm{MnO}_{2}$ Microrod Catalysts and Their Performance in Rapid Degradation of Dyes of High Concentration. Catal. Today 2014, 224, 154-162.

(41) Li, Y.; Cao, D.; Wang, Y.; Yang, S.; Zhang, D.; Ye, K.; Cheng, K.; Yin, J.; Wang, G.; Xu, Y. Hydrothermal Deposition of Manganese Dioxide Nanosheets on Electrodeposited Graphene Covered Nickel Foam as a High-Performance Electrode for Supercapacitors. J. Power Sources 2015, 279, 138-145.

(42) Wang, Y.; Zhong, H.; Hu, L.; Yan, N.; Hu, H.; Chen, Q. Manganese Hexacyanoferrate $/ \mathrm{MnO}_{2}$ Composite Nanostructures as a Cathode Material for Supercapacitors. J. Mater. Chem. A 2013, 1, 2621.

(43) Guo, M.-X.; Bian, S.-W.; Shao, F.; Liu, S.; Peng, Y.-H. Hydrothermal Synthesis and Electrochemical Performance of $\mathrm{MnO}_{2} /$ Graphene/Polyester Composite Electrode Materials for Flexible Supercapacitors. Electrochim. Acta 2016, 209, 486-497.

(44) Tang, X.; Li, Y.; Huang, X.; Xu, Y.; Zhu, H.; Wang, J.; Shen, W. $\mathrm{MnO}_{\mathrm{x}}-\mathrm{CeO}_{2}$ Mixed Oxide Catalysts for Complete Oxidation of Formaldehyde: Effect of Preparation Method and Calcination Temperature. Appl. Catal., B 2006, 62, 265-273.

(45) Ponrouch, A.; Marchante, E.; Courty, M.; Tarascon, J.-M.; Palacín, M. R. In Search of an Optimized Electrolyte for Na-Ion Batteries. Energy Environ. Sci. 2012, 5, 8572.

(46) Zhao, J.; Zhao, L.; Chihara, K.; Okada, S.; Yamaki, J.; Matsumoto, S.; Kuze, S.; Nakane, K. Electrochemical and Thermal Properties of Hard Carbon-Type Anodes for Na-Ion Batteries. J. Power Sources 2013, 244, 752-757.

(47) Komaba, S.; Murata, W.; Ishikawa, T.; Yabuuchi, N.; Ozeki, T.; Nakayama, T.; Ogata, A.; Gotoh, K.; Fujiwara, K. Electrochemical Na Insertion and Solid Electrolyte Interphase for Hard-Carbon Electrodes and Application to Na-Ion Batteries. Adv. Funct. Mater. 2011, 21, 3859-3867.

(48) Pandit, B.; Pande, S. A.; Sankapal, B. R. Facile SILAR Processed $\mathrm{Bi}_{2} \mathrm{~S}_{3}$ :PbS Solid Solution on MWCNTs for High-performance Electrochemical Supercapacitor. Chin. J. Chem. 2019, 37, 1279-1286.

(49) Pande, S. A.; Pandit, B.; Sankapal, B. R. Facile Chemical Route for Multiwalled Carbon Nanotube/Mercury Sulfide Nanocomposite: High Performance Supercapacitive Electrode. J. Colloid Interface Sci. 2018, 514, 740-749.

(50) Pandit, B.; Sharma, G. K.; Sankapal, B. R. Chemically Deposited $\mathrm{Bi}_{2} \mathrm{~S}_{3}: \mathrm{PbS}$ Solid Solution Thin Film as Supercapacitive Electrode. J. Colloid Interface Sci. 2017, 505, 1011-1017.

(51) Pande, S. A.; Pandit, B.; Sankapal, B. R. Vanadium Oxide Anchored MWCNTs Nanostructure for Superior Symmetric Electrochemical Supercapacitors. Mater. Des. 2019, 182, 107972.

(52) Pandit, B.; Sankapal, B. R.; Koinkar, P. M. Novel Chemical Route for $\mathrm{CeO}_{2} /$ MWCNTs Composite towards Highly Bendable Solid-State Supercapacitor Device. Sci. Rep. 2019, 9, 5892.

(53) Pandit, B.; Devika, V. S.; Sankapal, B. R. Electroless-Deposited Ag Nanoparticles for Highly Stable Energy-Efficient Electrochemical Supercapacitor. J. Alloys Compd. 2017, 726, 1295-1303.

(54) Niu, Y.; Xu, M.; Dai, C.; Shen, B.; Li, C. M. Electrospun Graphene-Wrapped $\mathrm{Na}_{6.24} \mathrm{Fe}_{4.88}\left(\mathrm{P}_{2} \mathrm{O}_{7}\right)_{4}$ Nanofibers as a HighPerformance Cathode for Sodium-Ion Batteries. Phys. Chem. Chem. Phys. 2017, 19, 17270-17277.

(55) Rajagopal, R.; Ryu, K.-S. Homogeneous $\mathrm{MnO}_{2} @ \mathrm{TiO}_{2}$ CoreShell Nanostructure for High Performance Supercapacitor and Li-Ion Battery Applications. J. Electroanal. Chem. 2020, 856, 113669.

(56) Cheng, F.; Zhang, T.; Zhang, Y.; Du, J.; Han, X.; Chen, J. Enhancing Electrocatalytic Oxygen Reduction on $\mathrm{MnO}_{2}$ with Vacancies. Angew. Chem., Int. Ed. 2013, 52, 2474-2477.
(57) Johnson, C. S.; Dees, D. W.; Mansuetto, M. F.; Thackeray, M. M.; Vissers, D. R.; Argyriou, D.; Loong, C.-K.; Christensen, L. Structural and Electrochemical Studies of $\alpha$-Manganese Dioxide $(\alpha$ $\mathrm{MnO}_{2}$ ). J. Power Sources 1997, 68, 570-577.

(58) Lundie, M.; Šljivančanin, Ž.; Tomić, S. Electronic and Optical Properties of Reduced Graphene Oxide. J. Mater. Chem. C 2015, 3, 7632-7641.

(59) Smeu, M.; Hossain, M. S.; Wang, Z.; Timoshevskii, V.; Bevan, K. H.; Zaghib, K. Theoretical Investigation of Chevrel Phase Materials for Cathodes Accommodating Ca ${ }^{2+}$ Ions. J. Power Sources 2016, 306, 431-436.

(60) Aydinol, M. K.; Ceder, G. First-Principles Prediction of Insertion Potentials in Li-Mn Oxides for Secondary Li Batteries. J. Electrochem. Soc. 1997, 144, 3832-3835.

(61) Tompsett, D. A.; Islam, M. S. Electrochemistry of Hollandite $\alpha$ $\mathrm{MnO}_{2}$ : $\mathrm{Li}$-Ion and $\mathrm{Na}$-Ion Insertion and $\mathrm{Li}_{2} \mathrm{O}$ Incorporation. Chem. Mater. 2013, 25, 2515-2526.

(62) Rong, Z.; Malik, R.; Canepa, P.; Sai Gautam, G.; Liu, M.; Jain, A.; Persson, K.; Ceder, G. Materials Design Rules for Multivalent Ion Mobility in Intercalation Structures. Chem. Mater. 2015, 27, 60166021. 